\title{
The Attack Frequency of Gnathonemus petersii towards Electrically Silent (Denervated) and Intact Conspecifics, and towards Another Mormyrid (Brienomyrus niger)
}

\author{
Bernd Kramer \\ Fachbereich Biologie, Universität Konstanz, Konstanz, \\ Federal Republic of Germany
}

Summary. 1. Aggression experiments were performed with Gnathonemus petersii. Three kinds of stimulus fish were used in random order to elicit attacks: (1) intact conspecifics, (2) electrically silent (operated) conspecifics, and (3) the mormyrid Brienomyrus niger.

2. The aggression indices for the two experiments with B. niger and the intact conspecific, i.e. the two electrically active fish, were similar $(p>0.4)$, whereas the index for the experiment with the silent conspecific was about one half of the two others $(p<0.01$, Fig. 2$)$.

3. In none of the three experimental conditions can the behavior sequence displayed by $G$. petersii be described by a random model, i.e. the occurrence of a given act depended on at least the preceding act $(p<0.001$, Tables $1-3$ ), as in a first-order Markov chain. For every behavior recognized, the distribution of following acts on a given act found in one group of experiments was significantly different from the same distribution found in one of the two other groups of experiments (Table 4).

4. The behavioral sequences, displayed by the experimental subjects, exhibited redundancies which were only slightly different when an intact $(35 \%)$ or an electrically silent conspecific (33\%) were present (Table 5). A considerable difference between both experiments was found on comparing the information $T(x ; y)$ which is common to a preceding behavior $x$ and a following behavor $y$ : in the silent conspecific experiment $T(x: y)$ was more than twice the value found in the intact conspecific experiment $(0.65$ and 0.28 bit, respectively). In the $B$. niger experiment $T(x ; y)$ was found to be low $(0.24$ bit). In contrast to both conspecific series of experiments, the redundancy value was also low $(23 \%)$. A high degree of redundancy of the behavioral sequence in spite of a low amount of internal constraint-both considered to be of prime importance in a communication system-were shown by the experimental $G$. petersii in the presence of intact conspecifics only.

5 . There were considerable differences in the electrical discharge activities of B. niger and G. petersii (Figs. 4-6). B. niger did not display a Preferred Latency Response to G. petersii's pulses (Fig. 7). 
6. The results show that by conspecific electric signals information is transmitted which significantly influences the behavior of a recipient $G$. petersii. These signals seem to be strictly species-specific.

\section{Introduction}

Fresh water bony fishes of the gymnotid and mormyrid families are known to use their electric organ discharge (EOD) for object location (reviews Bennett, 1971; Szabo and Fessard, 1974; Scheich and Bullock, 1974) and communication purposes (see review Scheich and Bullock, 1974; literature not covered in this review: Bauer, 1974; Bauer and Kramer, 1974; Kramer, 1974; Bell et al., 1974; Russell et al., 1974; Westby, 1974, 1975; Hopkins, 1975; Kramer and Bauer, 1976; Kramer, 1976; Kramer, in press). The work on communication showed that specific EOD patterns occur associated with certain behaviors, and that detailed temporal relationships may exist between the spike trains of two interacting fish. Furthermore, the conditions of artificial, electrical stimulation which are effective in eliciting approaches and other patterns of behavior have been analyzed mainly in some gymnotids.

Until now, no attempt seems to have been made to determine in a denervation experiment whether or not the social behavior, displayed by an intact weakly electric fish towards an operated partner, is affected by the partner's lack of electric cues. If the EOD plays an important role in communication, its presence or absence in a partner should greatly influence the behavior of a recipient intact individual. In order to recognize the influence, the behavior displayed towards an operated conspecific has to be compared with that towards an intact conspecific.

A mormyrid ( $G$. petersii) was chosen for this study, since in this group of weakly electric fish the electric organ, situated in the caudal peduncle, can easily be silenced by a section of the spinal cord at the cranial end of the caudal peduncle (Belbenoit, 1970).

The electric displays exhibited during social behavior are well analyzed in G. petersii (Bauer, 1972, 1974; Bauer and Kramer, 1973, 1974; Kramer, 1974; Bell et al., 1974; Russell et al., 1974; Kramer and Bauer, 1976; Kramer, in press).

The question arises whether the (electric) information exchanged is speciesspecific (as the complex activity patterns suggest), or if the mere presence or absence of an electric organ in another fish (with similar discharge characteristics) determines its "attractiveness" and hence the occurrence of interactions. It was hoped that this question could be decided by performing heterospecific experiments using intact specimens of $B$. niger, in addition to the experiments outlined above. The electrical activity of $B$. niger had to be analyzed, so that the (electrical) stimulus situation was known for comparisons to be made.

\section{Material and Methods}

Animals and Apparatus

Eleven Gnathonemus petersii $(9.4-11.5 \mathrm{~cm}$, weighing 6.9-11.2 g) and nine Brienomyrus miger (formerly Gnathonemus niger; see Taverne, 1971) $(8.8-9.8 \mathrm{~cm}$, weighing $6-11.4 \mathrm{~g})$ were used in this study. 
Fig. 1. Waveforms of the discharges of $B$. niger (abore; base-line superimposed), and of $G$. petersii (below). Head-positivity up

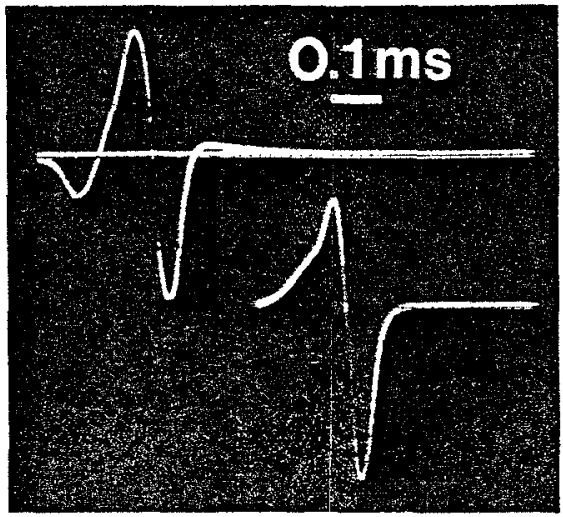

Normally, the fish were maintained together in 300-I aquaria (one for each species) which were planted and supplied with a layer of gravel and many porous-pot hiding places. Water temperature of the experimental and the home tanks was maintained at $26^{\circ} \mathrm{C}$, electrical resistivity ranged from $2.5 \mathrm{k} \Omega \cdot \mathrm{cm}$ to $2.9 \mathrm{k} \Omega \cdot \mathrm{cm}$. Total hardness was $0.8 \mathrm{mg} \mathrm{CaO}$ plus $\mathrm{CaSO}_{7} / 1(0.5 \mathrm{mg} \mathrm{CaO} / 1) ; \mathrm{pH}$ was 8.2. The water was power-flltered by synthetic fiber and peat. A $12 \mathrm{~h} / 12 \mathrm{~h}$ light-dark cycle was used both for the experimental and the home tanks. The fish were fed daily on live Chironomus larvae, small fresh water crustaceans, or Tubifer worms.

Head-to-tail peak-to-peak EOD voltages, measured in water, ranged from 1.25 to $3.6 \mathrm{~V}$ in $G$. petersin, and from 0.5 to $2.1 \mathrm{~V}$ in $B$.niger (water conditions: $25^{\circ} \mathrm{C} .3 \mathrm{k} \Omega-\mathrm{cm}$ ). The method of EOD recording was essentially the same as described in Kramer (1974). The pulse trains were analyzed on a 1000 address digital analyzer (Biomac, Data Laboratories, Ltd.), and on a Nicolet 1070 signal averaging system (Nicolet Instrument Corp.). The data stored in these devices were output on BCD paper tapes which were read and the data transferred to magnetic tape files in the computer centre of the University of Konstanz. The data stored on these tapes were used as the input to programs written in Fortran IV. These programs computed inter-pulse interval histograms, post-stimulus time histograms from the pulse trains of two fish together with the random distributions and tests for significance of differences, and serial correlograms (for details see Kramer, 1974).

The data where two electrically intact fish were kept together in one tank (Figs. 4c, 5d, 7) were obtained by measuring interspike intervals on film by hand. since it was not possible to separate the discharges of $B$. niger and $G$. petersii electronically. Film recordings were done by winding the film past the open shutter of the camera at $1000 \mathrm{~mm} / \mathrm{s}$. The intervals, determined to tenths of a ms with a vernier scale, were punched on cards so that the programs mentioned above could process the data further.

The experimental tank measured $1.0 \times 0.4 \times 0.5 \mathrm{~m}(2001)$. A voice record of the behavior of the two interacting fish was made with a tape recorder.

Figure 1 shows the waveforms of the discharges of both $B$. niger and $G$. petersii. The pulse emitted by $B$. niger differs from the short (approx. $0.35 \mathrm{~ms}$ ), biphasic discharge of $G$. petersii by a marked head-negative potential which precedes the two main phases of the discharge, and by a relatively long-lasting after-potential of low amplitude, so that the total duration of the discharge is approx. $0.5 \mathrm{~ms}$.

\section{Experimental Procedure}

Successive five days' series of three experiments per day were performed with seven G. petersii, each of which had been habituated to the experimental tank, which was supplied with a hiding place, for at least three days prior to the experiment. The hiding place in the experimental tank was a $24.5 \mathrm{~cm}$ length of a $7.4 \mathrm{~cm}$ diameter transparent plastic piping which was readily accepted by all of the fish during day. The experiments were made at 9:00 h., 13:00 $\mathrm{h}$ and 17:00 h. In 
random order, either an intact $G$. petersii, an operated $G$. petersii or an intact B. niger was put into the tank of the experimental fish - with the restriction that no fish should be put into the tank more than once a day. The behavior of the resident fish only was recorded, since in G. petersii motor patterns may be produced at such a high rate that it was not possible to describe reliably two-act sequences between individuals.

The pattern of behavior sequences displaced by the experimental animals, as described by the transition matrices Tables 1-3, were tested for significance of differences as compared with a random model. The usual way to calculate expected frequencies for each transition is to multiply the relative occurrence of the preceding act with the relative occurrence of the following act and to multiply the result with the grand total of all observed acts. It was not possible to apply this procedure to the present data, since several cells of the matrices are empty. All of these are in the descending main diagonal, i.c. in those cells in which entries are made for repetitions of the same act. Some of these cannot occur, e.g. after a stop a different behavior has to occur before stop may be counted again. Because of the cells which cannot be occupied, the calculation of expected values must be altered so that the row and column totals add up correctly without figures appearing in the empty cells (for a detailed discussion of this topic, see Slater, 1973). Goodman (1968) gives a method whereby this may be done by the means of an iterative technique. A computer program written by Prof. J. Wandnacher (Univ. Darmstadt) which uses this method was available at the University of Konstanz. Other statistical methods used are indicated in the text.

\section{Results}

\section{Behavioral Repertoire}

The behavioral components were defined as follows:

1. Approach (Ap). One fish approached the other but stopped or veered away before contact occurred.

2. Butt. A movement directed at another fish resulting in contact. From small wounds in the skin and from scales floating in the water it was obvious that biting occurred frequently. When the partners were close to each other a series of butts might be displayed, often by lateral strokes with the head. When an approach which resulted in a butt was initiated at a distance, the butt usually was a severe blow.

3. Lateral Display. Two fish in a parallel or "antiparallel" position close to each other.

4. Tail Lash. During lateral display, one of the fish (or both) may direct lateral blows of the tail against the body of the other.

5. Circling. One fish swam around the other.

6. Stop. This was counted when any kind of movement stopped, except when the fish performed a lateral display or hid in its tube.

7. Swimming $(\mathrm{Sw})$. Forward locomotion which was not directed at the partner.

8. Swimming Backwards (SwBackw). G. petersii may also swim backwards.

9. Probing ( $P r$ ). The fish probed the ground or objects with its chin appendage.

10. Hiding (Hid). The fish swam into its hiding tube. 


\section{Component Frequencies Displayed in the Three Stimulus Situations}

This section deals with the question whether or not the operated G. petersii and the heterospecific $B$. niger, used as stimulus fish, effectively modulate the frequencies of the experimental animal's responses, as compared to the results of the encounters where an intact $G$. petersii was used as a stimulus fish.

Figure 2 shows the outcome of the three series of experiments. The experimental animal displayed significantly less butts towards the silent G. petersii than it did in the presence of the intact G. petersii or B. niger (Wilcoxon matchedpairs signed-ranks test and Walsh test; Siegel, 1956). There is no significant difference when the results for the intact $G$. petersii and $B$. niger are compared with each other. The approach score was also lowest for the silent $G$. petersii; the difference intact-silent $G$. petersii is significant, whereas the difference $B . n i$ ger-silent $G$. petersii is just below the $5 \%$ level of significance.

In order to simplify the results related to aggressive behavior, an "aggression index" was calculated which uses both measures of attack and combines them by arbitrarily giving an approach half the weight of a butt (Fiedler, 1967). The aggression index for the silent $G$. petersii is by far lower than and significantly different from the two other indices (randomization test for matched pairs; Siegel, 1956). The difference between the intact G.petersii index and the $B$. niger index is insignificant $(p>0.4)$. An analysis using a weighting factor

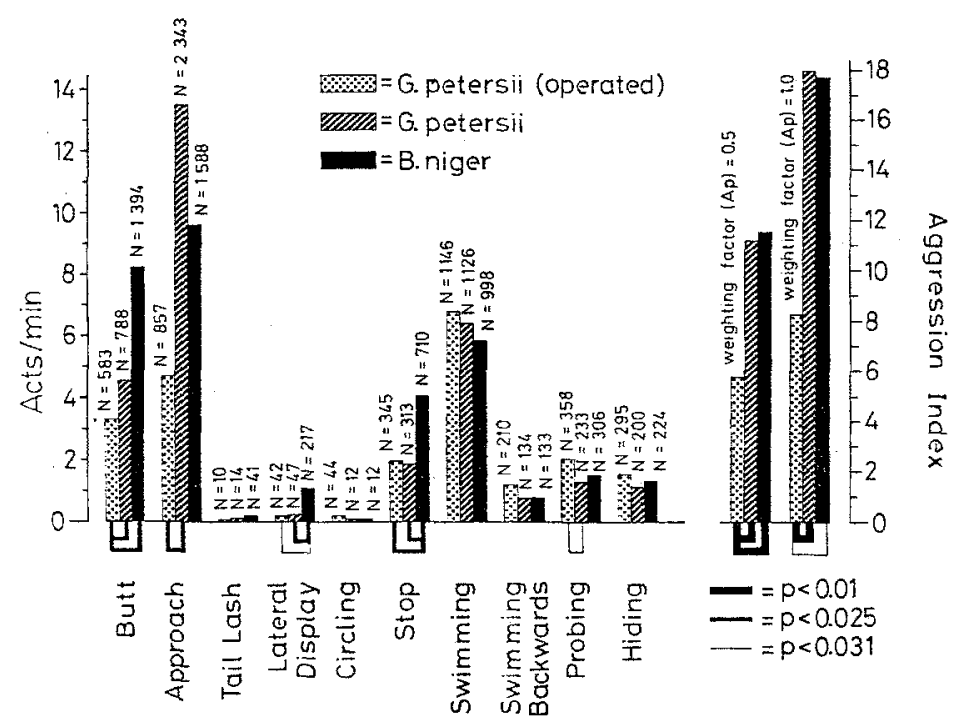

Fig. 2. Behavior displayed by the experimental $G$. petersii $(N=7)$ in the presence of a silent conspecific, an intact conspecific, and of a $B$. niger. Left ordinate: component mean frequencies; abscissa: behavioral categories recognized; right ordinate: shows two aggression indices for each experiment, calculated according to two different procedures: (1) weighting factor $(A p)=0.5$ gives the number of butts, each tallied as 1 , plus the number of approaches, each tallied as 0.5 , per min; (2) weighting facto $(A p)=1.0$ gives the same information, except that an approach has the same weight as a butt, i.e. 1. Significant differences are indicated below the base-line 
of one is also presented in Figure 2. Weighting factor zero has already been discussed (Fig. 2, butt). A significant difference between the scores for the electrically silent $G$. petersii on one hand and the two intact fishes on the other was found also for these weighting factors.

Among the other social behaviors analyzed (tail lash, lateral display, and circling), lateral display was exhibited significantly more often towards $B$. niger than in the presence of the two other fish. There was no significant difference between the scores for the intact and the silent $G$. petersit.

Among the "non-social" behaviors recognized (swimming, stop, swimming backwards, probing and hiding) only two (stop and probing) exhibit differential results between stimulus situations. The frequency of stop displayed in the presence of $B$. niger was almost twice the values recorded for the two $G$. petersii. Probing was exhibited more often in the experiment with the silent $G$. petersii than when the intact $G$. petersii was present; the $B$. niger score does not differ significantly from the two others.

The effect of the stimulus fish may also be expressed in terms of the mean rate of all components observed. An isolated $G$. petersii displayed a very low activity of approximately 0.5 acts (hiding, probing, swimming backwards, swimming, stop) per min (2-h recording); this rose to a mean 22.2 acts $/ \mathrm{min}$ in the presence of a silent conspecific. Both an intact conspecific $(29.8 \mathrm{acts} / \mathrm{min}$, $\mathrm{p}<0.01)$ and a $B$. niger $(32.1$ acts/min, $\mathrm{p}<0.025)$ elicited a considerably higher mean rate of components (Wilcoxon matched-pairs signed-ranks test). The difference between the two electrically active fish is insignificant.

\section{Sequential Analyses}

a) Comparison of Transition Frequencies

The effect of communication may be seen by a change in behavior. In most instances, the method of analysis of component frequencies is too crude to describe fully or even to detect a change. For example, when a coin is tossed twenty times, component frequency analysis does not distinguish between an outcome of ten heads followed by ten tails, and a regular alternation of heads and tails (or any other sequence with symmetrical outcome).

Baerends et al. (1955) studied sequential effects in the transition from one behavior (preceding act) to the next (following act). By this method, differences in the facilitated combinations of motor patterns may be revealed, even when the component frequencies displayed by two animals or one animal under different conditions are similar.

Some of the components shown in Figure 2 were grouped together in the sequence tables (Tables $(-3)$ because of their low rates. These were tail lash. lateral display and circling which form the group "other acts" (which means "other social acts than butt and approach"). This grouping is meaningful because of the close temporal correlation of these acts. By this grouping, the original $10 \times 10$ matrices were brought down to $8 \times 8$ matrices and the problem of zero-expected frequencies, as discussed e.g. in Westby (1975), was avoided so that a $\chi^{2}$-test for significance was applicable to the data.

Observed frequencies for each possible transition are given in Tables 1-3 for the three stimulus situations. From these tables, transition diagrams were drawn (Fig. 3). In these diagrams, circles 

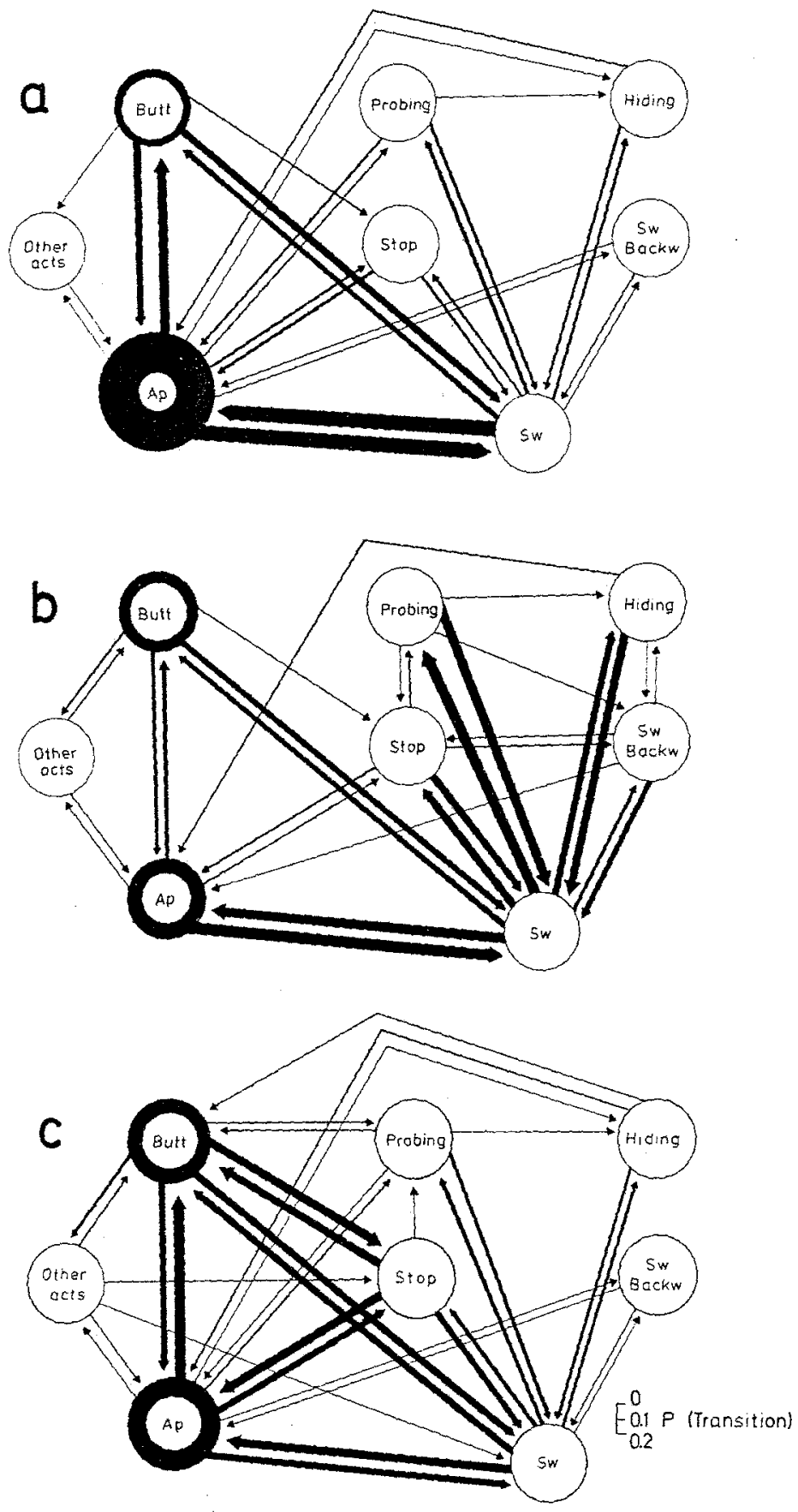

Fig. 3a-c. Transition diagram for agonistic behavior sequences, displayed by $G$. petersii. a Behavior displayed towards an intact conspecific, $b$ behavior displayed towards a silent conspecific, $\mathrm{c}$ behavior displayed towards a $B$. niger. Width of arrar: proportional to transition probability as shown. Ap, approach; Sw; swimming; SwBackw; swimming backwards; Other acts. scores for tail lash, lateral display and circling grouped together 
represent the activities displayed by the fish. The arrangement of the circles is not significant, except that social acts were grouped together to the left, non-social acts to the right. The (unconditional) probabilities associated with the transitions from one behavior to another are represented by the width and the direction of connecting arrows. The probability with which a behavior is repeated is indicated by the width of the circle.

In the transition diagram which shows the behavior of $G$. petersii towards an intact conspecific (Fig. $3 \mathrm{a}$ ), the predominant importance of the transitions from and to, as well as within, social behaviors is immediately visible. Butt and especially approach were extensively performed on their own (see also Table 1). A comparison with the transition diagram representing the experiment with the silent G. petersii (Fig. $3 \mathrm{~b}$ ) immediately shows the much greater importance of transitions between non-social behaviors. At first sight, the transition diagram for the B. niger experiment (Fig. 3c) resembles Figure 3a by the small frequencies of transitions between non-social behaviors. A conspicuous difference to both Figures $3 a$ and $b$ is the importance of the stop node which competes with the $\mathrm{Sw}$ node in its function as the main link between social and non-social behaviors, as it had been clearly established in Figures $3 \mathrm{a}$ and $\mathrm{b}$.

A more detailed approach to the analysis of the observed sequence of behavioral events is to observe whether or not the probabilities of different acts depend on the preceding act. Here, the matrix of observed transition frequencies is compared with that which would be expected if all behavioral acts were independent of one another. The results are presented in Tables 1-3. The hypothesis that the behavior of the experimental animals consists of independent events is rejected for the three series of experiments $\left(p<0.001, \chi^{2}\right.$-test), i.e. the probabilities of the different acts did in fact depend on the preceding act, as in a first-order Markov chain.

In the above analysis, $G$. petersii was found to display a sequence of behavior which cannot be described by a random model whatever stimulus fish was used. As a next step the hypothesis was tested that the three sequences of behavior, displayed in the presence of the three stimulus fish, are not different from each other. This was done by comparing the distribution of following acts on a given act, found in one group of experiments, with the same distribution taken from one of the two other groups of experiments, in a $2 \times \mathrm{k}$ contingency table. The results are shown in Table 4 . For every behavior recognized, the distribution of following acts found in one group of experiments was significantly different from the same distribution found in the two other groups of experiments.

\section{b) Redundancy and Internal Constraint in the Behavioral Sequences}

The question arises as to the nature of the differences described in the preceding section. A mathematical tool for characterizing various parameters of stochastic series of events, such as behavior sequences, is given by information theory (Wiener, 1948; Shannon and Weaver, 1949; Miller and Frick, 1949; Quastler, 1958; Attneave, 1974, among many others). In particular, a measure of the reduction of uncertainty which is associated with the occurrence of a behavior 
Table 1. Transition frequency distribution of 5200 agonistic behavior sequences in $G$. petersii, as displayed towards an intact conspecific. Expected frequencies are shown in brackets

\begin{tabular}{|c|c|c|c|c|c|c|c|c|c|c|}
\hline \multirow[b]{2}{*}{$\begin{array}{l}\text { Preceding } \\
\text { act }\end{array}$} & \multicolumn{10}{|c|}{ Following act } \\
\hline & & $u+t$ & App & prooch & Stop & Swimming & $\begin{array}{l}\text { Swimming } \\
\text { backwards }\end{array}$ & Probing & Hiding & Other acts \\
\hline Butt & 210 & $(117.5)$ & 240 & $(353.5)$ & $47(48.3)$ & $256(168.1)$ & $5(20.5)$ & $6(36.2)$ & $0(29.5)$ & $20(10.3)$ \\
\hline Approach & 323 & $(354.7)$ & 1284 & $(1067.4)$ & $110(145.8)$ & $491(507.6)$ & $45(62.0)$ & $56(109.2)$ & $29(89.2)$ & $29(31.1)$ \\
\hline Stop & 17 & $(49.7)$ & 140 & $(149.5)$ & & $98 \quad(71.1)$ & $19(8.7)$ & $17(15.3)$ & $15 \quad(12.5)$ & $5(4.4)$ \\
\hline Swimming & 188 & $(165.8)$ & 502 & $(498.8)$ & $122(68.1)$ & $2(237.2)$ & $42(29.0)$ & $130(51.0)$ & $118(41.7)$ & $2(14,5)$ \\
\hline $\begin{array}{l}\text { Swimming } \\
\text { backwards }\end{array}$ & 3 & $|20.6|$ & 46 & $(62.1)$ & $(8.5)$ & $57 \quad(29.5)$ & & & $(5.2)$ & $1(1.8)$ \\
\hline Probing & 13 & $(36.6)$ & 68 & $(110.2)$ & 8. $(150)$ & $112 \quad(52.4)$ & $(6.4)$ & & (9.2) & $1[32]$ \\
\hline Hiding & 16 & (31.1) & & $(937)$ & $0 \quad(12.8)$ & $101 \quad(44.6)$ & $12 \quad(5.4)$ & $10 \quad(9.6)$ & & $0(27)$ \\
\hline Other acts & 17 & $(10.9)$ & 27 & (32.9) & $(4.5)$ & $9 \quad(15.7)$ & $1 \quad(1.9)$ & $\begin{array}{ll}0 & 13.4\end{array}$ & (2.8) & $11(1.0)$ \\
\hline
\end{tabular}

Table 2. Transition frequency distribution of 3772 agonistic behavior sequences in $G$. petersii, as displayed towards a silent conspecific. Expected frequencies are shown in brackets

\begin{tabular}{|c|c|c|c|c|c|c|c|c|c|}
\hline \multirow[b]{2}{*}{$\begin{array}{c}\text { Preceding } \\
a c t\end{array}$} & \multicolumn{9}{|c|}{ Following act } \\
\hline & & $u t t$ & Approach & Stop & Swimming & $\begin{array}{l}\text { Swimming } \\
\text { backwards }\end{array}$ & Probing & Hiding & Other acts \\
\hline Butt & 249 & $(85.4)$ & $92\{125.1\}$ & $25(52.3)$ & $154(172.1)$ & $6(32.1)$ & $3(58.1)$ & $0(43.8)$ & $54(14.1)$ \\
\hline Approach & 100 & (125.2) & $384(183.5)$ & $44(76.7)$ & $271(252.4)$ & $16 \cdot(47.1)$ & $8(85.2)$ & $8(64.2)$ & $24(20.6)$ \\
\hline Stop & 11 & $(55.4)$ & $50(81.1)$ & & $186(111.6)$ & $37(20.8)$ & $47(37.7)$ & $13(28.4)$ & $0(9.1)$ \\
\hline Swimming & 151 & $(167.3)$ & $229(245.1)$ & $190(102.4)$ & $3(337.2)$ & $90(62.9)$ & $272(113.8)$ & $204(85.8)$ & $3(27.5)$ \\
\hline $\begin{array}{l}\text { Swimming } \\
\text { backwards }\end{array}$ & 8 & $(32.4)$ & $22(47.5)$ & $28(19.8)$ & $110 \quad(65.3)$ & & & $20(16.6)$ & $2(5.3)$ \\
\hline Probing & 8 & (56.9) & $16\{83.4\}$ & $32(34.9)$ & $230(114.8)$ & $34(21.4)$ & & $30(29.2)$ & $\begin{array}{ll}0 & (9.4)\end{array}$ \\
\hline Hiding & 14 & $(46.7)$ & $35(68.4)$ & $4(28.6)$ & $210 \quad(94.2)$ & $23(17.6)$ & $9(31.8)$ & & $0(7.7)$ \\
\hline Other acts & 42 & $(13.6)$ & $25(20.0)$ & (8.3) & $11 \quad(27.5)$ & $1(5.1)$ & $0 \quad(9.3)$ & $(7.0)$ & $13 \quad(2.2)$ \\
\hline
\end{tabular}

in a behavioral sequence may be calculated, as well as the amount of internal constraint in the system which causes the sequential dependencies, demonstrated to exist by the above $\chi^{2}$-analysis (Tables $1-3$ ).

From the frequencies of the components, the average information $H$ (or uncertainty, or entropy) in bit which is associated with the occurrence of a behavior $x$ may be estimated according to 
Table 3. Transition frequency distribution of 5368 agonistic behavior sequences in G. petersii, as displayed towards a $B$. niger. Expected frequencies are shown in brackets

\begin{tabular}{|c|c|c|c|c|c|c|c|c|}
\hline \multirow[b]{2}{*}{$\begin{array}{l}\text { Preceding } \\
\mathrm{cct}\end{array}$} & \multicolumn{8}{|c|}{ Following oct } \\
\hline & Butt & Approach & Stop & Swimming & $\begin{array}{l}\text { Swimming } \\
\text { backwards }\end{array}$ & Probing & Hiding & Other acts \\
\hline Butt & 445 (331.5) & $212(373.6)$ & $280(195.8)$ & $231(234.4)$ & $10(29.8)$ & $45(74.2)$ & $16(54.4)$ & $110 \quad(55.3)$ \\
\hline Approach & $345(374.3)$ & $610(421.8)$ & $198(221.0)$ & $220(254.6)$ & $24(33.6)$ & $54(83.8)$ & $29(61.4)$ & $43(62.4)$ \\
\hline Stop & $150(200.1)$ & $275(225.5)$ & & 198 (141.5) & $18(18.0)$ & $29(44.8)$ & $16(32.8)$ & $10 \quad(33.4)$ \\
\hline Swimming & $230(232.7)$ & $289(262.3)$ & $137(137.4)$ & $6(164.5)$ & 33. (20.9) & $135(52.1)$ & $108(38.2)$ & $11 \quad(38.8)$ \\
\hline $\begin{array}{l}\text { Swimming } \\
\text { backwards }\end{array}$ & $11 \quad(29.7)$ & $24(33.4)$ & $13(17.5)$ & $38(21.0)$ & & & $17 \quad(4.9\}$ & $7(4.9)$ \\
\hline Probing & $61 \quad(73.1)$ & $35(82.4)$ & $18 \quad(43.2 !$ & $.125 \quad(51.7)$ & $15(6.6)$ & & & $1(12.2)$ \\
\hline Hiding & $28 \quad(56.9)$ & $34(64.1)$ & $6 \quad(33.6)$ & $119(40.2)$ & $19(5.1)$ & $16 \quad(12.7)$ & & $0(9.5)$ \\
\hline Other ccts & $85 \quad(56.8)$ & $48(64.0)$ & $30 \quad(33.5)$ & $23 \quad(40.1)$ & $0 \quad(5.1)$ & $0\{12.7\}$ & 1 (9.3) & $44(9.5)$ \\
\hline & & & $x^{2}$ & 1583.2 & $d f=45$ & & & \\
\hline
\end{tabular}

Table 4. Comparison of the distribution of following acts on a given act, found in one group of experiments, with the same distribution, found in one of the two other groups of experiments, as indicated. This was done for all behaviors recognized by casting the data in a $2 \times \mathrm{k}$ contingency table $(\mathrm{k}=8)$. Where the individual cell frequency of a following act was too low, grouping with a related behavior was necessary. Note that for every behavior recognized the distribution of following acts on a given act found in one group of experiments is significantly different from the same distribution found in one of the two other groups of experiments

\begin{tabular}{|c|c|c|c|}
\hline \multirow[b]{2}{*}{$\begin{array}{l}\text { Preceding } \\
\text { act }\end{array}$} & \multicolumn{3}{|c|}{ Comparison of experiment } \\
\hline & $\begin{array}{l}\text { silent / intoct } \\
\text { G. petersii }\end{array}$ & $\begin{array}{l}\text { silent G. petersii / } \\
\text { G. niger }\end{array}$ & $\begin{array}{l}\text { intact G.petersii / } \\
\text { B. niger }\end{array}$ \\
\hline Butt & $\begin{array}{c}x^{2}=90.45 \quad \text { df }=6 \\
p<0.009\end{array}$ & $\begin{array}{cc}x^{2}=119.23 & d f=7 \\
p<0.001 & \end{array}$ & $\begin{array}{c}x^{2}=22959 \\
p<0.001\end{array}$ \\
\hline Approach & $\begin{array}{c}x^{2}=62.42 \\
p<0.001\end{array}$ & $\begin{array}{c}\mathrm{X}^{2}=168.22 \quad \mathrm{df}=7 \\
p<0.001\end{array}$ & $\begin{array}{c}x^{2}=204.66 \\
p<0.001\end{array}$ \\
\hline Stop & $\begin{array}{cc}x^{2}=94.79 & d f=6 \\
p<0.001 & \end{array}$ & $\begin{array}{c}x^{2}=201.19 \\
p<0.001\end{array}$ & $\begin{array}{c}x^{2}=48.35 \\
p<0.001\end{array}$ \\
\hline Swimming & $\begin{array}{c}x^{2}=211.14 \\
p<0.001\end{array}$ & $x^{2}=121.55 \quad 0.001 \quad d f=7$ & $\begin{array}{rl}x^{2}=57.97 & d f=6 \\
p & <0.001\end{array}$ \\
\hline $\begin{array}{l}\text { Swimming } \\
\text { backwards }\end{array}$ & $\begin{array}{c}x^{2}=31.92 \\
p<0.001\end{array}$ & $\begin{array}{c}x^{2}=25.19 \\
p<0.001\end{array}$ & $\begin{array}{c}x^{2}=25.0 \\
p<0.001\end{array}$ \\
\hline Probing & $x^{2}=83.50 \quad d f=5$ & $\begin{array}{c}x^{2}=84.31 \\
p<0.001\end{array}$ & $\begin{array}{c}x^{2}=42.87 \\
p<0.001\end{array}$ \\
\hline Hiding & $\begin{array}{c}x^{2}=35.98 \\
p<0.001\end{array}$ & $\begin{array}{rl}x^{2}=22.74 & d f=5 \\
p & <0.001\end{array}$ & $\begin{array}{r}x^{2}=20.28 \\
p<0.01\end{array}$ \\
\hline other & $\begin{array}{r}x^{2}=16.79 \\
p<0.01\end{array}$ & $\begin{array}{c}x^{2}=16.10 \\
p<0.01\end{array}$ & $\begin{array}{l}x^{2}=10.14 \\
p<0.05\end{array}$ \\
\hline
\end{tabular}


the Shannon-Wiener formula:

$$
H(x)=-\sum_{i} p(i) \log _{2} p(i)
$$

where $p(i)$ is the probability of each behavior $x_{i}$, as estimated empirically. Table 5 shows the results obtained for the three series of experiments. By comparing these values with the theoretical maximum which is $\log _{2} n$ ( $n$ equiprobable categories of $x$ ) the relative entropy $R$ is obtained:

$$
R(x)=H(x) / \log _{2} n
$$

Table 5 shows that the uncertainty associated with the occurrence of a behavior was considerably smaller in the experiment with an intact conspecific as a partner $[R(x)=0.75$, or $75 \%$ of the maximum uncertainty] as compared with the two other experiments where the relative entropies are rather similar (0.89 and 0.86 ). In other words, the redundancy $C$ (which is defined as $C=1-R$ ) of the three behavior sequences was $25 \%, 11 \%$, and $14 \%$, respectively.

These estimates of the average information $H(x)$ per component or of the relative entropy $R(x)$ are overestimates since the $\chi^{2}$-analysis presented above (Tables $1-3$ ) showed that sequential dependencies of (at least) first order existed in the behavior sequences. This means that part of the information contributed by a given component in a sequence was shared with the following component. Since this information applies in common to the specification of both the preceding and the following component it has to be subtracted from the uncertainty per component in order to yield the net information added by each component in the sequence (or the minimal amount of information necessary to specify the next component).

In order to calculate the net information per component, as well as the amount of information which is shared by two successive components, it is necessary to estimate the uncertainty associated with the two-part system or the joint occurrence of a behavior $x$ and a following behavior $y$. The joint uncertainty $H(x, y)$ is defined as

$$
H(x, y)=-\sum_{i j} p(i, j) \log _{2} p(i, j)
$$

where the $p(i, j)$ are the probabilities associated with the joint occurrence of $(x=i)$ and $(y=j)$. The joint uncertainty is compared to the sum of the individual uncertainties $H(x)$ and $H(v)$ (in an analysis of a stochastic series of events, $H(x)$ is, of course, equal to $H(y)$ except for end effects, since each behavior but the first and the last one is considered twice: as a following act $y$ and as a preceding act $x$ ). The deficit of the joint uncertainty $H(x, y)$ as compared with the sum of the individual uncertainties $H(x)$ and $H(y)$ is the amount of information $T(x ; y)$ which is shared by two successive components:

$$
T(x ; y)=H(x)+H(y)-H(x, y)
$$

The $T$-measure is a measure of the internal constraint in the system which leads to an association between $x$ and $y$. This is also shown by the coefficient of constraint $D(x ; y)=T(x ; y) / H(x)$ (cf. Attneave, 1974: Table 5) which measures the average information which is common to $x$ and $y$ expressed as a portion of the entropy of $x$. The coefficient of constraint therefore varies between $O$ ( $x$ and $y$ totally unrelated) and 1 (total specification of $y$ by $x$ ).

The strongest relatedness between a preceding and a following act was found in the experiment with the silent conspecific $(T(x ; y)=0.65$ bit, Table 5$)$ as compared with the experiments with the intact conspecific $(0.28 \mathrm{bit})$ and $B$. niger 
Tables 5 and 6. An information theory analysis of the behavior displayed by G. petersii in the presence of three different stimulus fish. See text

\begin{tabular}{|c|c|c|c|}
\hline \multirow[t]{2}{*}{5} & \multicolumn{3}{|c|}{ Experiment with } \\
\hline & intact conspecific & silent conspecific & B. niger \\
\hline Uncertainty of a behovior $H(x)$ in bit & 2.25 & 2.68 & 2.57 \\
\hline Relotive uncertainty & 075 & 0.80 & \\
\hline of a behovior $R(x)$ & 0.75 & 0.85 & d.86 \\
\hline Redundancy $C(x)$ & 0.25 & 0.11 & 0.14 \\
\hline Joint uncertointy $H(x, y)$ in bit & 4.21 & 4.69 & 4.89 \\
\hline Information shared $T\left(x_{i} y \mid\right.$ in bit & 0.28 & 0.65 & 0.24 \\
\hline $\begin{aligned} \text { Conditional uncertainty (ambiguity) } \\
\\
H_{x}(y) \text { in bit }\end{aligned}$ & 1.96 & 2.01 & 2.32 \\
\hline Caefficient of constraint $D\left(x_{i} y\right)$ & 0.12 & 0.24 & 0.09 \\
\hline $\begin{array}{l}\text { Relative uncertainty of o behavior } \\
\text { (considering first-order transitions) } R_{x}(y)\end{array}$ & 0.65 & 0.67 & 0.77 \\
\hline $\begin{array}{l}\text { Redundancy } \\
\text { (considering first-order transitions) } C_{x}(y)\end{array}$ & 0.35 & 0.33 & 0.23 \\
\hline
\end{tabular}

6

\begin{tabular}{|c|c|c|c|}
\hline \multirow[b]{2}{*}{$\begin{array}{l}\text { Preceding } \\
\text { behavior }\end{array}$} & \multicolumn{3}{|c|}{$\begin{array}{l}\text { Conditional. uncertainty } H \text { ilyt in bit of the next behavior } \\
\text { given that the preceding behavior is known }\end{array}$} \\
\hline & intact conspecific & $\begin{array}{l}\text { Experiment with } \\
\text { silent conspecific }\end{array}$ & B.niger \\
\hline Butt & 2.04 & 2.07 & 2.64 \\
\hline Approach & 1.94 & 2.00 & 2.32 \\
\hline Stop & 2.05 & 1.96 & 2.06 \\
\hline Swimming & 2.22 & 2.55 & 2.46 \\
\hline $\begin{array}{l}\text { Swimming } \\
\text { backwords }\end{array}$ & 2.01 & 2.10 & 2.57 \\
\hline Probing & 1.97 & 1.67 & 2.20 \\
\hline Hiding & 1.77 & 1.45 & 1.99 \\
\hline Other octs & 2.24 & 1.86 & 2.21 \\
\hline $\begin{array}{l}\text { Average } \\
\text { conditional } \\
\text { uncertainty } \\
H_{x}(y) \text { in bit }\end{array}$ & 1.96 & 2.01 & 2.32 \\
\hline
\end{tabular}


( 0.24 bit). These three $T$-values are all highly significant $(p<0.001)$, as shown by the $\chi^{2}$-analysis presented in Tables $1-3$.

The average uncertainty $H_{x}(y)$ concerning the following event $y$ given that the preceding event $x$ is known, can be calculated as the weighted average of the individual conditional uncertainties for each act $x_{i}$ :

$$
H_{x}(y)=-\sum_{i} p(i) \sum_{j} p_{i}(j) \log _{2} p_{i}(i)
$$

where the $p_{i}(j)$ are the conditional probabilities of $(y=j$ if $x=i)$, or $H_{x}(y)=H(x, y)=H(x)$ which is equivalent to $H_{x}(y)=H(y)-T(x ; y)$.

This information measure gives the net amount of uncertainty per component which remains after having subtracted the gain of certainty about $y$ from observing $x$ (last equation).

Table 5 shows rather similar values for the average conditional uncertainties $H_{x}(y)$ for the experiments with the silent and the intact conspecifics (2.01 bit and 1.96 bit, respectively); in the $B$.niger experiment a considerably higher value $(2.32$ bit) was found which means that the average uncertainty about the following event, given that the preceding event was known, was greater.

Table 6 also gives the individual conditional uncertainties. In each set of conditional uncertainties, there was one which did not (or did not greatly) reduce $H_{x}(y)$ as compared with $H(x)$. For example, from observing swimming backwards in the experiment with $B$. niger, no certainty was gained about the following act, since the uncertainty derived from the frequencies of the components alone was no greater $\left(H_{\mathrm{SwB}}(y)=2.57\right.$ bit, $H(x)=2.57$ bit $)$. All the other conditional entropies in each set were smaller than $H(x)$, however, and contributed to the reduction of $H_{x}(y)$ as compared with $H(x)$, according to their size and weight.

No gross inhomogeneities in the data appeared when the analysis was carried out separately for two subgroups, by dividing the group of seven experimental subjects into a group of four and a group of three animals. In the worst case (the group of experiments with the intact conspecifics) there was a $5.6 \%$ difference between the conditional entropies of the two subgroups $(2.5 \%$ and $2.2 \%$ for the silent conspecific experiment and the heterospecific experiment, respectively).

The redundancies of the behavioral sequences $\left(C_{x}(y)=1-H_{x}(y) / \log _{2} n\right)$ found in the experiments with the intact conspecific, the silent conspecific, and $B$. niger thus rose from $25 \%, 11 \%$ and $14 \%$ to $35 \%, 33 \%$ and $23 \%$, respectively, by considering first-order transitions. It is clear that the reduction of uncertainty per component by the information shared by two acts was greatest for the silent conspecific experiment because the $T$-value was highest.

\section{Electrical Actinity of B. niger}

In a discussion of the reasons which cause $G$. petersii to behave differently towards a $B$. niger than towards an intact conspecific, it is important to observe whether or not differences exist in the electrical discharge activities between the two species, and what the relationships between the pulse trains of the 


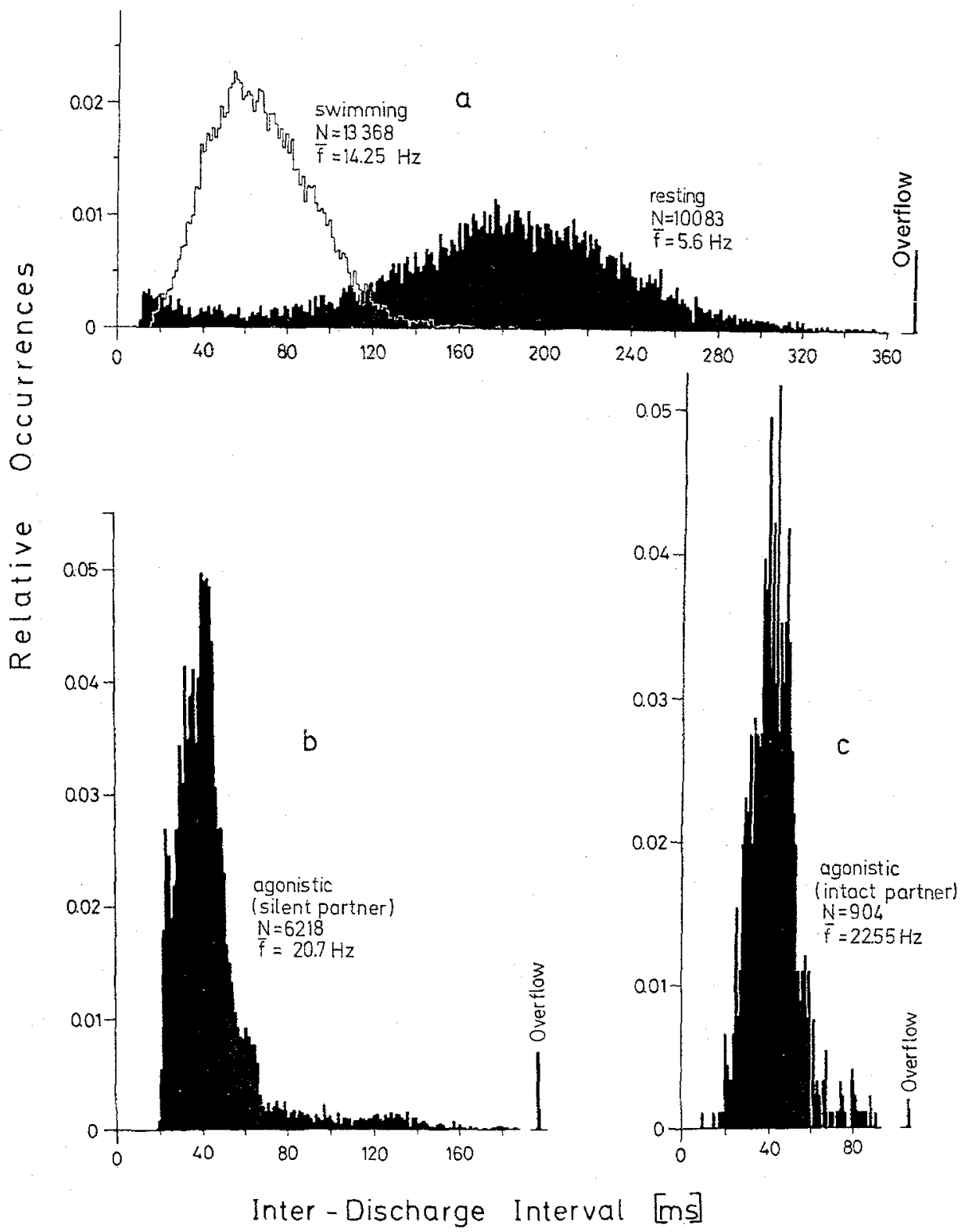

Fig. 4 a-c. Interpulse interval histograms of a $B$. niger. a black histogram: activity of an isolated $B$. niger, resting completely immobile (except for gill movements) on the bottom of its hiding tube; white histogram: activity of an isolated $B$. niger displayed during swimming about the aquarium. b histogram displayed by a $B$. niger while attacking a silent (operated) $G$. petersii, put into the $\operatorname{tank}$; $\mathbf{c}$ shows the same as $\mathbf{b}$, except that the G.petersii put into the tank was discharging. Note high variation, low mean discharge rate, and bimodal distribution of interval lengths in the resting fish, as compared with a swimming or an attacking fish which displayed only one preferred discharge rate. The four histograms are normalized to cover the same area, i.e. equal areas are the same densities of probability. $N$, total number of intervals analysed; $\bar{f}$ nean discharge rate. Bin width in a and b $1.28 \mathrm{~ms}$, in c $1.0 \mathrm{~ms}$ 


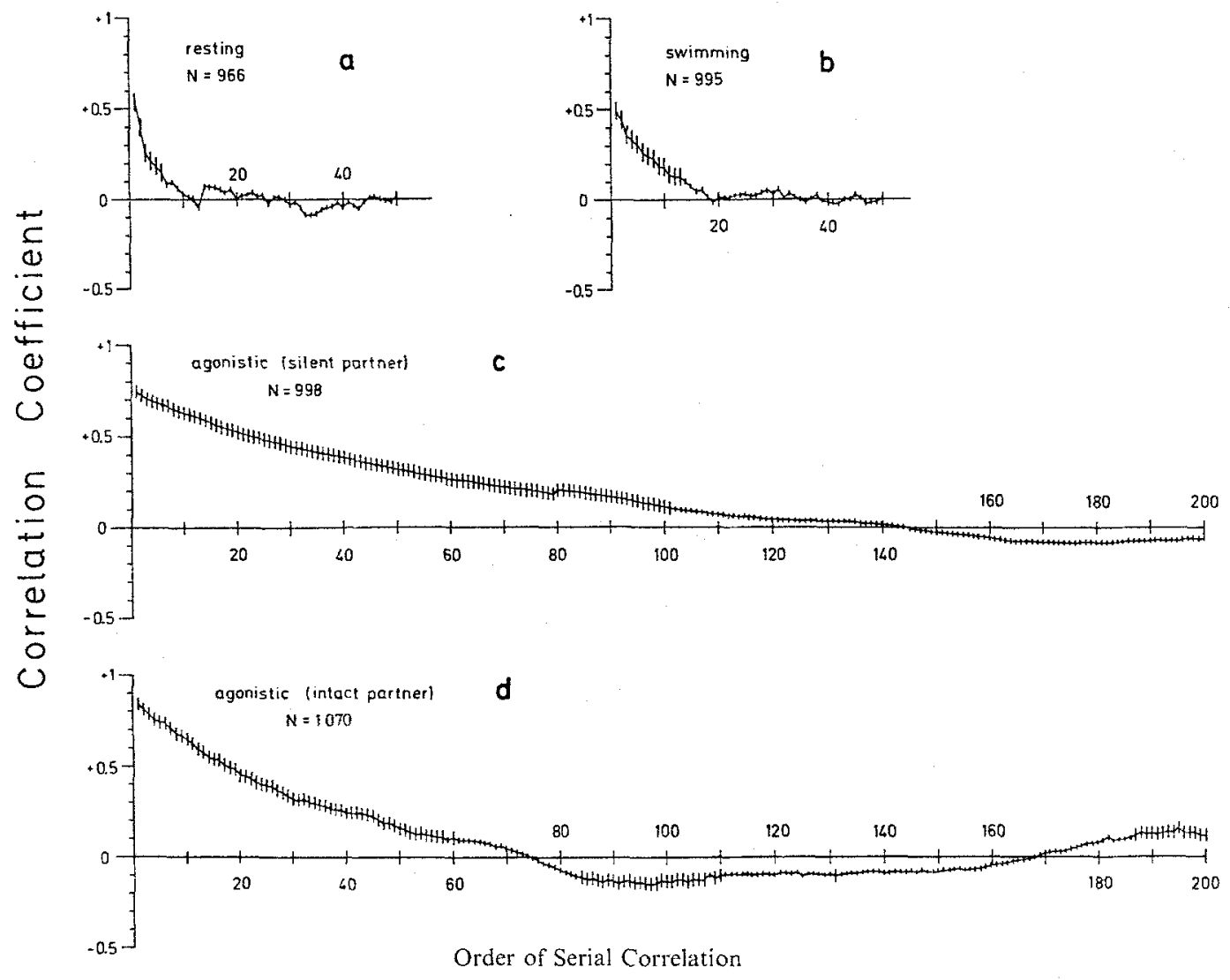

Fig. 5. Serial correlograms of interpulse interval sequences of $B$. niger emitted during four different behavioral situations, as indicated. $N$, total number of intervals analyzed. Large vertical bars, correlation coefficients significant at a non-parametric Wald-Wolfowitz confidence level of $p<0.001$

two fishes are. The following results are based on four (swimming activity: five) individuals of $B$. niger for the analysis of the activity of isolated fish, and eight animals attacking silent $G$. petersii. Eight pairs of individuals (16 animals) were used to study the relationships between discharge trains.

An immobile $B$. niger displayed a histogram with two modes, a small one at about 14 and a very prominent one at about $180 \mathrm{~ms}$ (Fig. $4 \mathrm{a}$, black histogram). Especially the latter mode may vary considerably, causing the mean discharge rate (see also Moller, 1970) to range from 4 to $8 \mathrm{~Hz}$. A serial correlation analysis of the order in which intervals of different length occur (method: see Kramer, 1974) shows that runs of 6 to up to 45 intervals tended to be similar in length (Fig. 5a). With an increasing number of intervals separating two intervals, the correlation coefficient decreased. This means that there is no short-term compensation in the interval-length regulation mechanism as shown in $G$. petersii (Kramer, 1974, Fig. 3c) in the same behavioral state.

A swimming, isolated $B$. niger displayed a histogram with only one mode at about 50 to $70 \mathrm{~ms}$ (Fig. $4 \mathrm{a}$, white histogram). Mean discharge rates ranged 
from 10 to $16 \mathrm{~Hz}$. As in the resting activity, the correlation coefficients decreased with an increasing number of intervals separating two intervals (Fig. 5 b). Runs of intervals which displayed a significant tendency to be similar in length ranged from 7 to 53 intervals. Histogram shape and rhythm of discharge were quite similar to the activity displayed by $G$. petersii during swimming (Kramer, 1974; Kramer and Bauer, 1976).

A $B$. niger which attacked an electrically silent $G$. petersii displayed a very marked tendency for consecutive intervals to remain similar in length. This tendency may involve from about 50 to more than 200 intervals (Fig. 5c). The resulting histograms display one or two modes and are heavily skewed to the right (Fig. $4 \mathrm{~b}$ ). Mean discharge rates ranged from 13 to $21 \mathrm{~Hz}$.

A $B$. niger which attacked an electrically intact $G$. petersii displayed a similar range of mean discharge rates (13 to $23 \mathrm{~Hz}$ ). The histograms with high mean discharge rate tended to have only one mode (Fig. 4c). Successive interval length regulation may be completely lacking (no correlation at all in two cases); in six other cases significant positive correlation coefficients (up to approx. 60) were found (Fig. 5c). The cause for this may be different dominance relationships between the partners.

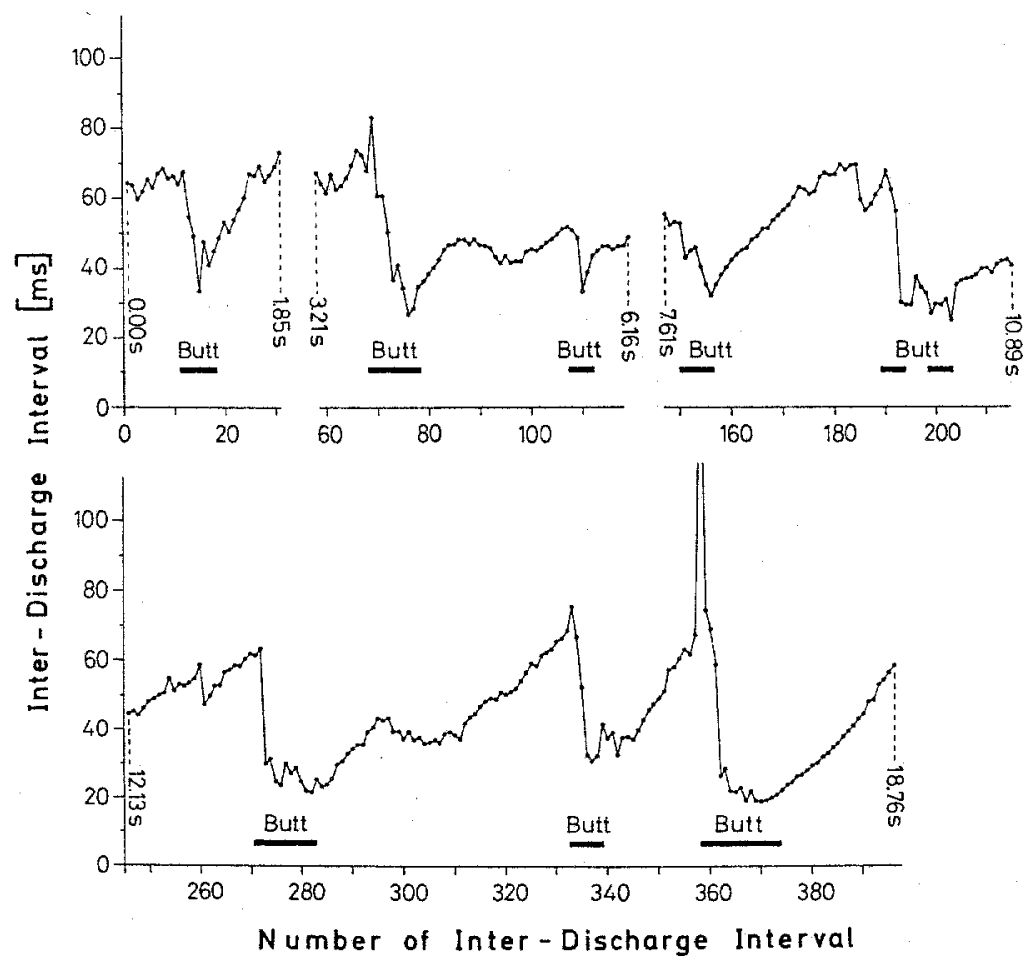

Fig. 6. Sequential representation of a $B$. niger's discharge activity during agonistic behavior, directed at a silent $G$. petersii. Each point is one interval, plotted sequentially on the abscissa. The ordinate is the length of each interval. Note that during overt attack interval length decreased rapidly (i.e. discharge rate rose). Periods without attacks and discharge rate accelerations were omitted as indicated. The time course in $s$ is indicated at several points by dotted lines 

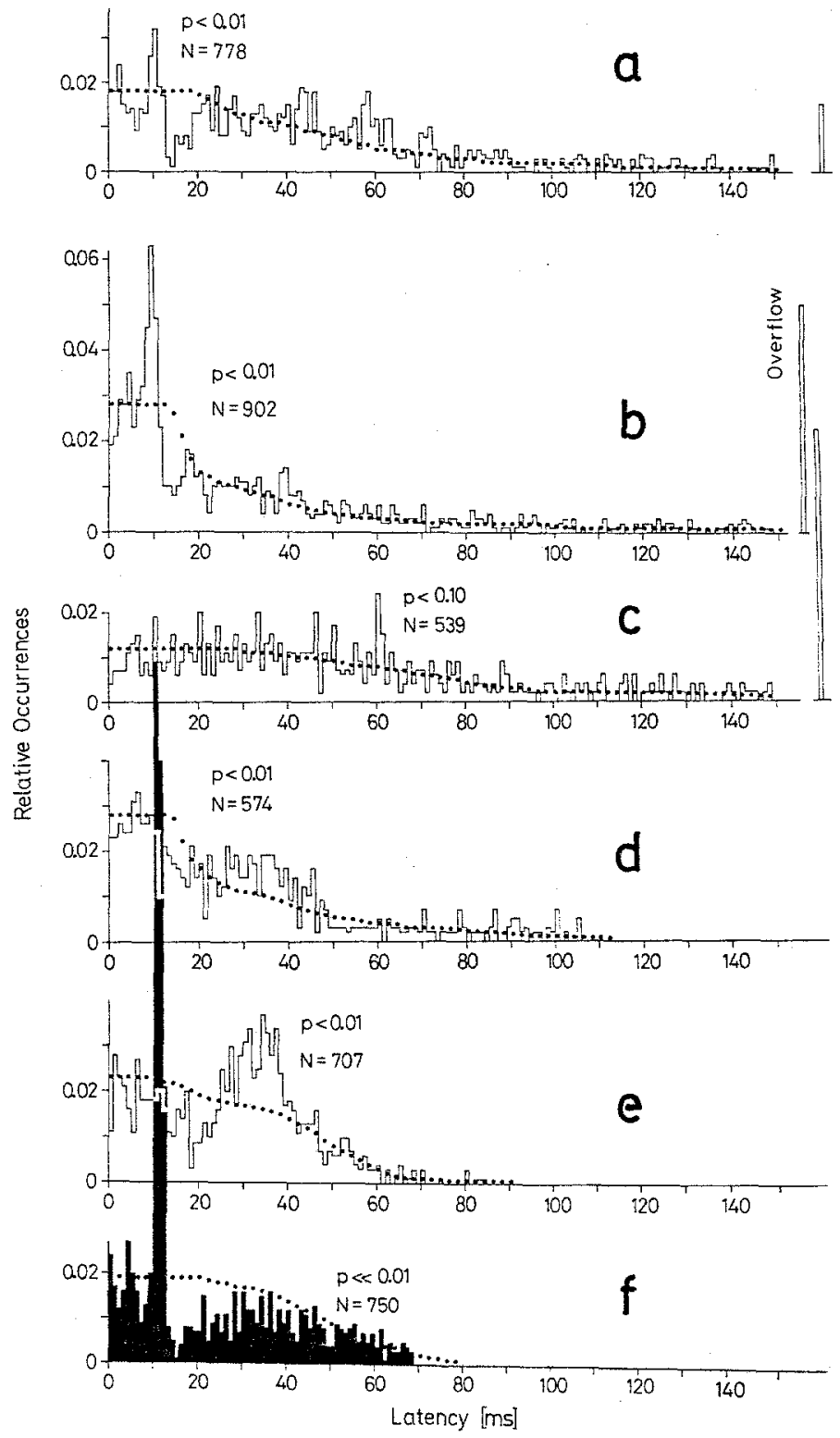

Fig. 7a-f. Histograms of the latencies of $B$. niger pulses to $G$. petersii pulses during agonistic behavior (a-e). $N$, total number of pulses emitted by $B$. niger. f shows the opposite, i.e. the latencies of $G$. petersii pulses to $B$. niger pulses. $N$, total number of pulses emitted by $G$. petersii. The distributions obtained were tested for significance of differences as compared to the random distributions, indicated by dots, by a Kolmogorov-Smirnov test. Note that B. niger did not exhibit a specific latency preference as did $G$. petersii (f). The significant differences from random in a-e (except c) are due to the tendency of $G$. petersii to maintain a discharge latency of about $12 \mathrm{~ms}$ to the pulses of B. niger (f) 
The discharge activity displayed by $B$. niger during and between attacks is shown in Figure 6. Between attacks, interval length ranged from approx. $40-70 \mathrm{~ms}$; during attack, a marked discharge rate acceleration took place. Within 1 to 11 intervals, the highest discharge rate was attained. The shortest intervals displayed during an attack ranged from 33 to $19 \mathrm{~ms}$. The high discharge rate was not maintained and levelled off rather quickly; the decrease was, however, less rapid than the increase.

No consistent latency relationship of $B$. niger pulses to $G$. petersii pulses was found in eight encounters of eight different pairs of animals (Fig. 7). Five of these latency distributions differ significantly from random (for method of calculation, see Kramer, 1974); from these distributions it is not possible to establish a clear latency preference. In contrast to this, $G$. petersii consistently showed a significant latency preference of about $9-13 \mathrm{~ms}(\mathrm{p} \ll 0.01$, KolmogorovSmirnovtest) to $B$. niger pulses which obviously caused the deviations from the random distributions in five of the eight $B$. niger latency curves (for discussion of this point see Kramer, 1974, p. 226).

\section{Discussion}

Comparing the frequencies of behavioral components displayed by $G$. petersii in the presence of a conspecific, of an electrically silent conspecific, and of another weakly electric fish species (Fig. 2), the non-social behavioral components (with the exception of stop) were found to be most frequent for the silent $G$. petersii experiment, in spite of a substantially lower mean frequency of acts, as compared with the values for the two other groups of experiments. The high scores of non-social behaviors displayed in the presence of the silent $G$. petersii, contrast with the low scores of the social components butt and approach the silent $G$. petersii received.

The question arises whether these changes in the behavior of the experimental subjects are a result of lack of electric stimulation or a result of other kinds of abnormal stimuli from the operated stimulus fish. As it was not possible to record simultaneously the behavior of the stimulus fish and the behavior of the experimental animals (see Methods), no quantitative data are available which might decide this problem. However, a qualitative test was performed by putting intact conspecifics and $B$. niger into the aquaria of the operated fish prior to the experiments (three months post operationem). The operated fish attacked the intruders by butts and approaches much as intact conspecifics would do. Used as stimulus fish in the aquaria of the experimental animals, the operated and the intact conspecifics both swam continuously about the aquarium, exploring the corners and trying to escape from the territory owner as soon as it came close to them. So in conclusion there were, if at all, no gross differences between the behavior of intact and electrically silent conspecific stimulus fish, and the behavior of the operated stimulus fish cannot be qualified as "abnormal".

$B$. niger probably received more butts and less approaches than the intact $G$. petersii because of the pronounced tendency of $B$. niger to rest during the 
light period, even when it is put into a new environment. G. petersii, on the other hand, tends to explore also during the day after having been transferred into another tank.

The high lateral display score for $B$. niger, which is significantly above the values for the two other fish, is probably due to the same reason. With a partner that displayed a tendency to rest, the experimental $G$. petersii exhibited more lateral displays than with one of the two other fish present which tried to escape in most cases, as soon as they were being approached.

There were no significant differences between the scores in the frequencies of two other social behaviors for the three stimulus fish, tail lash and circling. The frequencies associated with both behaviors were extremely low. As the fish used in this study were small and probably not much older than one year, this may be related to sexual maturity (cf. Kramer and Bauer, 1976).

These findings seem to show that a silent conspecific was less effective in eliciting a change from socially irrelevant to socially significant behavior in $G$. petersii. From the results follows also that the heterospecific $B$. niger was as effective (or even more effective) in eliciting attacks as a conspecific although the electrical activities of $B$. niger and $G$. petersii are quite distinct (p. 437). Therefore, what seems to be important is whether the other fish discharges or not (especially when the frequency content of the discharge is similar, cf. Fig. 1), irrespective of the pulse patterns displayed.

This picture changed considerably when sequential relationships between components were analyzed. As shown in Table 4, for every preceding behavior displayed by the experimental animal, the distribution of following acts depended significantly on the stimulus fish used.

A dependency on any earlier acts than the preceding act was not tested for two reasons: (I) shortage of data. A sequence with $n=8$ different components will give $n^{3}=512$ triplet types, and thus very extensive data are required before reasonable numbers of each are expected. (2) It is not reasonable to take Markov chain analysis far when the sequence analyzed is unlikely to be stationary (as are most behavioral data), for "data which appear to follow a Markov chain of high order could also be interpreted as unstationary and vice versa" (Slater, 1973). Likewise, considering second-order transitions might further increase the redundancies of the behavior sequences given in the lower part of Table 5, as in the sequence of the general type $A \rightarrow B \rightarrow C$ not only $B$ might share information with $\mathrm{C}$, but also $\mathrm{A}$ with $\mathrm{C}$.

The certainty $T(x ; y)$ about the following act gained from observing the preceding act, displayed by the experimental subject, was only slightly different in the experiments with the intact conspecific and $B$.niger as stimulus fish (Table 5; Fig. 8). However, the remaining conditional uncertainty $H_{x}(y)$ about the following behavior was substantially greater [the redundancy $C_{x}(y)$ considerably lower] in the heterospecific experiment than in the two other series of experiments. Thus it was $B$. niger which elicited the most unpredictable behavior of the experimental animals. In the presence of a silent or an intact conspecific, the redundancies of the behavior sequences exhibited by the experimental animals were rather similar ( 33 and $35 \%$, respectively), although there are important differences in the structures of the underlying information systems. With an 


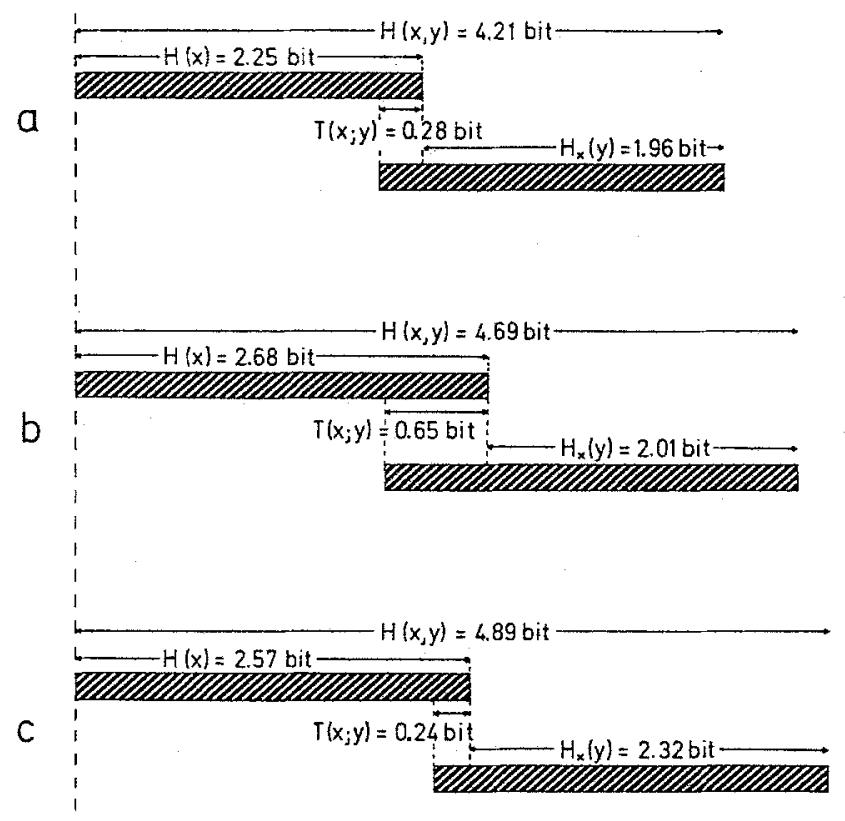

Fig. 8a-c. A graphical representation of the results of an information theory analysis of the behavior displayed by an experimental $G$. petersii in the presence of an intact conspecific (a), a silent conspecific (b), and a heterospecific $B$. niger (c). See text

intact conspecific as stimulus fish, the experimental subjects displayed a rather stereotyped behavior, resulting in a low $H(x)$. The silent conspecific elicited a much more diversified behavior, resulting in a high $H(x)$. The extent to which the following behavior $y$ was specified by the nature of the preceding behavior $x$ was small in the intact conspecific experiment; this extent was considerably greater in the silent conspecific experiment. Therefore, the conditional uncertainties $H_{x}(y)$ about the following behavior are similar.

In conclusion, the electric signals of both the conspecific and the heterospecific stimulus fish reduced the amount of sequential constraint in the behavior displayed by the experimental subjects by a factor $<0.5$, as compared with the silent conspecific experiment. A low degree of internal constraint in the behavior-producing system of both partners seems to be a prerequisite for any successful communication, since sufficient freedom of choice is necessary in order to respond to a partner's behavior. Another prerequisite for communication seems to be a high degree of redundancy in the behavioral sequences, to allow time for the synchronization of partners in initially different behavioral and physiological states. A behavioral sequence which was characterized by a low amount of internal constraint and high redundancy was displayed by the experimental animals only when in tact conspecific stimulus fish were present. Therefore, it is concluded that conspecific electrical signals transmit specific information. The role of these signals may be especially important during reproductive behavior when it is crucial that the behavior of mates should be synchronized in these nocturnal animals. 
Acknowledgements. This work was supported by research grant Nos. $\mathrm{Kr} 446 / 3$ and 4 by the Deutsche Forschungsgemeinschaft. I wish to thank Prof. Dr. H. Markl for valuable suggestions and for critically reading the manuscript, and Miss E. Hoffmann for skilled technical assistance. Prof. Dr. D. Vorberg and W. Mohr kindly made available the computer program written by Prof. Dr. J. Wandmacher for the calculation of expected values in an incomplete transition matrix.

\section{References}

Attneave, F.: Informationstheorie in der Psychologie. Bern-Stuttgart-Wien: Hans Huber 1974

Baerends, G.P., Brouwer, R., Waterbolk, H.T.: Ethological studies on Lebistes reticulatus. 1. An analysis of the male courtship pattern. Behavior 8, 249-335 (1955)

Bauer, R.: High electrical discharge frequency during aggressive behaviour in a mormyrid fish, Gnathonemus petersii. Experientia 28, 669 (1972)

Bauer, R.: Electric organ discharge activity of resting and stimulated Gnathonentus petersii (Mormyridae). Behaviour 50, 306-323 (1974)

Bauer, R., Kramer, B.: Relations entre le comportement agressif du Mormyridé Gnathonemus petersii et sa décharge électrique. J. Physiol. (Paris) 67 (2), 240-241 A (1973)

Bauer, R., Kramer, B.: Agonistic behaviour in mormyrid fish: latency-relationship between the electric discharges of Gnathonemus petersii and Mormyrus rume. Experientia 30, 51-52 (1974)

Belbenoit, P.: Conditionnement instrumental de lélectroperception des objets chez Gnathonemus petersii (Mormyridae, Teleostei, Pisces). Z. vergl. Physiol. 67, 192-204 (1970)

Bell, C.C., Myers, J.P., Russell, C.J.: Electric organ discharge patterns during dominance related behavioral displays in Gnathonemus petersii (Mormyridae). J. comp. Physiol. 92, 201-228 (1974)

Bennett, M.V.L.: Electrolocation in fish. Ann. N.Y. Acad. Sci. 188, 242-269 (1971)

Fiedler, K.: Ethologische und neuroanatomische Auswirkungen von Vorderhimexstirpationen bei Meerbrassen (Diplodus) und Lippfischen (Crenilabrus, Perciformes, Teleostei). J. Hirnforsch. 9, 483-563 (1967)

Goodman, L.A.: The analysis of cross-classified data: independence, quasi-independence, and interactions in contingency tables with or without missing entries. J. Am. Stat. Ass. 63, 1091-1131 (1968)

Hopkins, C.D.: Electric communication in the reproductive behaviour of Sternopygus macrurus. Z. Tierpsychol. 35, 518-535 (1975)

Kramer, B.: Electric organ discharge interaction during interspecific agonistic behaviour in freely swimming mormyrid fish. A method to evaluate two (or more) simultaneous time series of events with a digital analyser. J. comp. Physiol. 93, 203-235 (1974)

Kramer, B.: Electric signalling during aggressive behaviour in Mormyrus rume (Mormyridae, Teleostei). Naturwissenschaften 63, 48 (1976)

Kramer, B.: Flight-associated discharge pattern in a weakly electric fish, Gnathonemus petersii (Mormyridae, Teleostei). Behav. 59, 88-95 (1976)

Kramer, B., Bauer, R.: Agonistic behaviour and electric signalling in a mormyrid fish, Gnathonemus petersii. Behav. Ecol. Sociobiol. 1, 45-61 (1976)

Miller, G.A., Frick, F.C.: Statistical behavioristics and sequences of responses. Psychol. Rev. 56, $311-324$ (1949)

Moller, P.: 'Communication" in weakly electric fish, Gnathonemus niger (Mormyridae). I. Variation of electric organ discharge (EOD) frequency elicited by controlled electric stimuli. Anim. Behav. 18, 768-786 (1970)

Quastler, H.: A primer on information theory. In: Symposium on information theory in biology (eds. H.P. Yockey, R.L. Platzman, H. Quastler), p. 3-49. New York: Pergamon Press 1958

Russell, C.J., Myers, J.P., Bell, C.C.: The echo response in Gnathonemus petersii (Mormyridae). J. comp. Physiol. 92, 181-200 (1974)

Shannon, C.E., Weaver, W.: The Mathematical Theory of Communication. Urbana: Univ. lllinois Press 1949

Scheich, H., Bullock, T.H.: The detection of electric fields from electric organs. In: Handbook of sensory physiology. Vol. III/3 (ed. A. Fessard), p. 201-256. Berlin-Heidelberg-New York: Springer 1974 
Siegel, S.: Nonparametric Statistics for the Behavioral Sciences. New York: Mc Graw Hill Book Co. Inc. 1956

Slater, P.J.B.: Describing sequences of behavior. In: Perspectives in ethology (eds. P.P.G. Bateson, P.H. Klopfer), p. 131-153. New York-London: Plenum Press 1973

Szabo, T., Fessard, A.: Physiology of electroreceptors. In: Handbook of sensory physiology. Vol. III/ 3 (ed. A. Fessard), p. 59-124. Berlin-Heidelberg-New York: Springer 1974

Taverne, L.: Note sur la systématique des poissons Mormyriformes. Le problème des genres Gnathonemus Gill, Marcusenius Gill, Hippopotamyrus Pappenheim, Cyphomyrus Myers et les nouveaux genres Pollimyrus et Brienomyrus. Rev. Zool. Bot. Afr. 84, 99-110 (1971)

Westby, G.W.M.: Comparative studies of the aggressive behaviour of two gymnotid fish. Anim. Behav. 23, 109-130 (1974)

Westby, G.W.M.: Has the latency-dependent response of Gymmotus carapo to discharge triggered stimuli a bearing on electric fish communication? J. comp. Physiol. 96, 307-341 (1975)

Wiener, N.: Cybernetics. New-York: Wiley 1948

Received June 29, 1976

B. Kramer

Fachbereich Biologie

Universität Konstanz

Postfach 7733

D-7750 Konstanz

Federal Republic of Germany

\section{Note Added in Proof}

An analysis of schooling behavior displayed by electrically silent Marcusenius cyprinoides has now appeared: Moller, P.: Electric signals and schooling behavior in a weakly electric fish, Marcusenius cyprinoides L. (Mormyriformes). Science 193, 697-699 (1976).

This paper also shows the great importance of electric signals in social behavior of mormyrids.

W. Heiligenberg recently showed that artificially stimulated $B$. niger try to minimize the probability of coincidences with foreign pulses by a Preferred Latency ("echo") Response in order to maintain their electrolocation ability of nearby moving objects. Heiligenberg, W. : Electrolocation and jamming avoidance in the mormyrid fish Brienomyrus. I. comp. Physiol. 109, 357-372 (1976). 